\title{
Tracking recruitment pathways of Chromis viridis in the Gulf of Aqaba using otolith chemistry
}

\author{
O. Ben-Tzvi ${ }^{1,2, *}$, M. Kiflawi ${ }^{1,3, * *}$, S. D. Gaines ${ }^{4}$, M. Al-Zibdah ${ }^{5}$, M. S. Sheehy ${ }^{4}$, \\ G. L. Paradis ${ }^{4,6}$, A. Abelson ${ }^{2, * *}$ \\ ${ }^{1}$ The Interuniversity Institute for Marine Sciences of Eilat, PO Box 469, Eilat 88103, Israel \\ ${ }^{2}$ Department of Zoology, George S. Wise Faculty of Life Sciences, Tel-Aviv University, Tel-Aviv 69978, Israel \\ ${ }^{3}$ Department of Life Sciences, Ben-Gurion University, Be'er Sheva 84105, Israel \\ ${ }^{4}$ Marine Science Institute, University of California Santa Barbara, Santa Barbara, California 93106, USA \\ ${ }^{5}$ Marine Science Station, University of Jordan and Yarmouk University, PO Box 195 Aqaba, Jordan \\ ${ }^{6}$ Department of Earth Science, University of California Santa Barbara, Santa Barbara, California 93106, USA
}

\begin{abstract}
Connectivity among coral reef fish populations is a key factor in governing the structure and dynamics of marine communities and should therefore be taken into account in management and conservation plans. Determining connectivity patterns is a challenging task, since direct tracking of larval trajectories is essentially impossible. During the last decade, however, there have been some significant achievements in the form of indirect tracking of larval sources. Some of these are based on trace elements incorporated into the otoliths of dispersing larvae, which may assist in the identification of natal origins and provide some information about larval trajectories. In this study an attempt was made to infer the dispersal trajectories of larval Chromis viridis (Pomacentridae) that recruit to populations along the northern Gulf of Aqaba (Red Sea). The patterns of trace-element signals found in otoliths (identified by laser ablation inductively coupled plasma mass spectrometry), complemented by the spatial structure in pelagic larval durations (PLD), suggest that the northern populations (i.e. Aqaba and Eilat) of $C$. viridis are seeded by larvae that disperse along more than one route from sources along the Saudi and Sinai (Egyptian) coasts. The study findings imply that any sound management plans or conservation measures for coral reefs in the Gulf of Aqaba should be regional, and should ideally involve collaboration among all the adjacent countries.
\end{abstract}

KEY WORDS: Connectivity $\cdot$ Larval stage $\cdot$ Laser ablation inductively coupled plasma mass spectrometry $\cdot$ LA-ICPMS $\cdot$ Trace-elemental signature $\cdot$ Red Sea

\section{INTRODUCTION}

The growing recognition of the deleterious effects of human pressure on coastal marine ecosystems has led to intensive promotion of marine conservation, with emphasis on coastal marine reserves (e.g. Roberts \& Hawkins 1997, Allison et al. 1998, 2003, Lubchenco et al. 2003). At present, individual marine reserves may provide insufficient protection since the scale of fundamental processes is often much greater than can be countered by the reserves (Palmer et al. 1996, Allison et al. 1998). Larval supply is a prominent example of one such large-scale process that can affect the efficacy of marine reserves via its effects on various processes, such as population replenishment and community development (Gaines \& Bertness 1993, Caley et al. 1996, Allison et al. 1998). The combination of planktonic lifespan of larvae and ocean currents that carry them can generate strong interconnections among sites and areas (Palmer et al. 1996, Roberts 1997). In coral reefs, for instance, strong connectivity among spatially distinct reef sites implies that local populations and communities are open and may depend on processes occurring elsewhere (Roberts 1997). 
In the literature on coral reef fish, considerable debate has taken place over whether populations are demographically open or closed (reviewed by Mora \& Sale 2002). Traditionally, local recruitment was assumed to be derived mainly from neighboring and distant reefs, rendering populations effectively open. However, recent studies have shown that, at least in some cases, locally derived larvae can contribute significantly to the seeding of local populations (Jones et al. 1999, 2005, Swearer et al. 1999, Warner \& Cowen 2002, Almany et al. 2007). It is worth noting that these studies utilized data obtained from tags in the fishes' otoliths. Some of these were artificial tags (Jones et al. 1999, 2005, Almany et al. 2007), while others were based on otolith microchemistry.

An increasing number of studies have been attempting to use otolith microchemistry in order to discriminate among reef-fish populations (Patterson et al. 1999, 2004a,b, Swearer et al. 1999, Lo-Yat et al. 2005, Patterson \& Kingsford 2005). While some studies seek to differentiate among natal grounds (e.g. Ruttenberg \& Warner 2006), others seek differences within recruiting cohorts that may be attributable to different origins or dispersal trajectories (e.g. Swearer et al. 1999). The spatial scale over which identifiable differences are generated can vary dramatically (Patterson et al. 2004a, Ruttenberg \& Warner 2006).

The main goal of this study was to infer the dispersal trajectories that seed Chromis viridis populations of the northern Gulf of Aqaba in the anticipation that these trajectories might provide an indication of the extent of connectivity of the studied population and its source locations. To address this aim, an attempt was made to

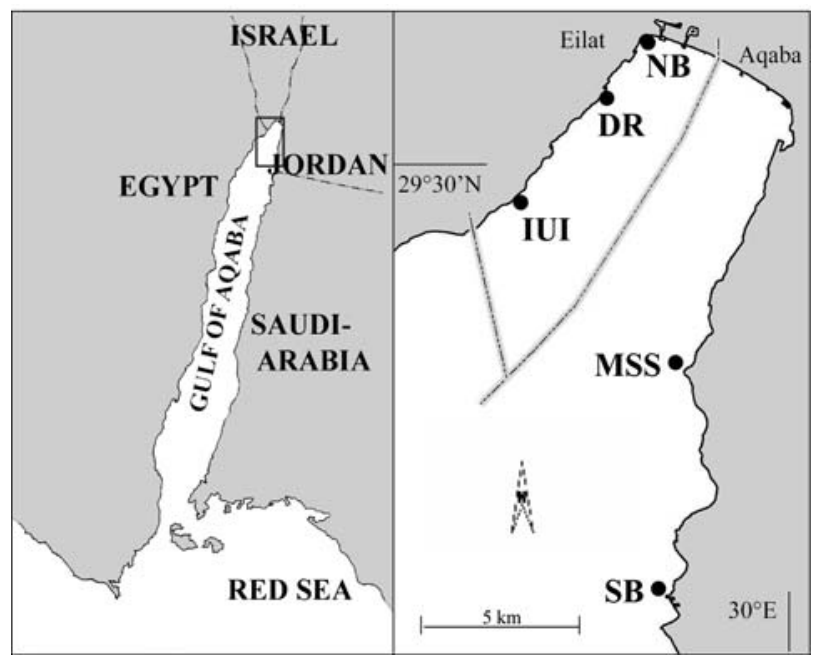

Fig. 1. Gulf of Aqaba region (left) and study sites in the northern tip of the gulf (right). Pelagic larval durations of the fish recruited to each site: IUI, $22 \mathrm{~d}$; DR, 22 and $26 \mathrm{~d} ; \mathrm{NB}, 22$ and $26 \mathrm{~d}$; MSS, $26 \mathrm{~d}$; SB, $26 \mathrm{~d}$ identify differences in otolith elemental profiles of newly settled recruits from several sites along the northern tip of the gulf (Eilat and Aqaba reefs), a coastline of about $35 \mathrm{~km}$ with a linear span of about $20 \mathrm{~km}$ (Fig. 1). The comparison of otolith elemental profiles was aided by a recently developed approach - palindrome sequence analysis (PaSA, Ben-Tzvi et al. 2007a) - in which relevant laser ablation inductively coupled plasma mass spectrometry (LA-ICPMS) data are identified through the symmetry of elemental signals about the otolith core, even when these fall below the accepted detection limit.

\section{MATERIALS AND METHODS}

Study area. The northern tip of the Gulf of Aqaba (Fig. 1) experiences a high volume of commercial and recreational activities. Several ports and marinas are found along the Jordanian and Israeli coastlines. There are numerous sources of contamination, including sewage, aquaculture and leakage of potassium and phosphates during cargo ship loading. Ongoing research has shown the northern gulf to be an ever-changing spatial mosaic of trace element concentrations (A. Paytan pers. comm.), most likely driven by the intense anthropogenic activity. Solution-based ICPMS analysis of the aragonite skeletons of sessile invertebrates has revealed higher long-term concentrations of contaminants (e.g. $\mathrm{Pb}, \mathrm{Cr}, \mathrm{Cu}, \mathrm{Va}$ and others) along the northernmost Eilat coastline than along the coastline $\sim 3 \mathrm{~km}$ further south (O. Ben-Tzvi, Y. Erel, A. Abelson unpubl. data).

Due to political restrictions, our study was limited to a small part of the gulf (along the coasts of Jordan and Israel). Our census and sampling, as well as other studies that we quote, are restricted accordingly. Anthropogenic activity along the Egyptian coast (west coast, $100 \mathrm{~km}$ south of Eilat) is as intensive as that of Aqaba and Eilat and thus it can be expected that similar water contamination occurs in that area too. However, this is not the case along the Saudi coast (east side, south of Aqaba), which is mostly deserted, with very low anthropogenic activity of any type.

Recruitment monitoring. The recruitment of fish to the reefs of the northern part of the Gulf of Aqaba is characterized by recruitment periods and pauses of different durations (Ben-Tzvi et al. 2007b). Recruitment was monitored by daily censuses of a fixed transect at IUI (see next paragraph), during which all recruits to 398 coral colonies in 2004 and 348 colonies in 2005 were counted (Ben-Tzvi et al. 2007b). Other sites were monitored weekly in order to spot new recruits, which can be easily identified by their size and color. We defined the period from the arrival of the first recruits until the next pause as a 'recruitment 
event.' The dates of the recruitment events were later confirmed based on otolith readings (see below).

Fish collection. Juvenile Chromis viridis were collected from 5 sites along the northern tip of the gulf (Fig. 1). Fish were collected in accordance with animal care and nature protection laws in Jordan and Israel, and with permits and supervision of the relevant authorities of both countries. Three of the sites were along the Israeli coastline: a patch reef with high abundance of several branching coral species on a moderate slope between 2 to $10 \mathrm{~m}$ depth at the Eilat marine laboratory (IUI); 3 isolated knolls on a sandy slope between 3 and $8 \mathrm{~m}$ depth near the Dolphin Reef (DR); and a group of knolls on a sandy plain at a depth of 3 to $4 \mathrm{~m}$ at the northwest end of the gulf (NB). The remaining 2 sites were in continuous reefs with a high diversity of corals (including many branching colonies of different species) along the Jordanian coast, one near the Saudi Border (SB) and the other at the Aqaba marine laboratory (MSS). Collections coincided with 4 recruitment events: September to October 2003; August to September 2004 (Early 04); October to November 2004 (Late 04); and October to November 2005 (in 2005 recruitment to Eilat started in September while in Aqaba recruitment started only in October). Although IUI and NB were sampled on each of these dates, DR was sampled only in 2004, and MSS and SB only in 2005. It should be emphasized, however, that whenever fish were collected, the collection at all sampled sites was executed within a few days and the fish were consequently from similar recruitment dates. Clove oil and hand nets were used to collect juveniles within 0 to $15 \mathrm{~d}$ of their settlement onto Acropora spp. colonies. The fish were transferred to shore alive and stored in $95 \%$ ethanol within 30 min of capture. Sample size varied among years and sites and ranged between 10 to 40 fish per site per recruitment event.

Estimating pelagic larval duration (PLD) and recruitment dates. It was found in a preliminary study that the increments are much clearer in the lapillar otolith than in the sagittal, while the number of increments was identical in both otoliths. Thus, the lapillar otoliths were chosen for microscope otolith reading. One lapillar otolith was removed from each fish, cleansed of soft tissue and glued onto an acrylic slide using low viscosity epoxy resin (Epo-Thin epoxy resin, Buehler). In most cases, we read the otoliths without polishing, but used $3 \mu \mathrm{m}$ and $1 \mu \mathrm{m}$ lapping film (Imperial, 3M) to improve resolution when necessary. Increments were counted directly on the microscope $(\times 500$ and $\times 1000)$, while separating between pre- and post-settlement counts. Average PLD and total age were calculated based on 3 independent readings of each otolith. Otoliths with a co-efficient of variation greater than $5 \%$, for either age (pre- or post-settle- ment), were discarded. Recruitment dates were backcalculated from post-settlement ages and, as far as possible, verified against field observations gathered daily at IUI throughout the entire recruitment season (May to January) of the years 2003-2004 and 2005-2006.

Otolith microchemistry. Sagittal otoliths are bigger than lapillar ones and their increments are wider. Thus, in the search for chemical differences across an otolith the wider increments provide better resolution and were thus chosen for this purpose. One sagitta was dissected from each fish and then cleansed of any organic tissue using dissecting pins, mounted with low viscosity epoxy resin (Epo-Thin epoxy resin, Buehler) with the sulcus side up, and polished to within 20 to $25 \mu \mathrm{m}$ of the core (for additional details see Ruttenberg et al. 2005). We found that for Chromis viridis collected immediately after recruitment (revealed by otolith readings), the last layer of resin above the core (in the middle of the sulcus) was removed when the distance to the core was between 22 and $24 \mu \mathrm{m}$. Thus, removing otolith material above this distance from the core exposes the level where the settlement mark is expected to be, while leaving intact the entire pelagic part of the otolith. The polished otoliths were further cleansed of any surface contaminants and organic components by soaking in semiconductor-grade $15 \%$ $\mathrm{H}_{2} \mathrm{O}_{2}$ and Suprapur $\mathrm{NaOH}(0.05 \mathrm{~N})$, followed by a series of ultrapure water ( $\mathrm{N}$-pure) rinse steps, and air drying in a class-100 (ISO class 5 equivalent) flow bench (Ruttenberg et al. 2005). Microchemical analyses of the treated samples used a Finnigan Element 2 double-focusing sector Inductively Coupled Plasma Mass Spectrometer (ICPMS) with VG UV Microprobe $266 \mathrm{~nm}$ laser ablation system (Ruttenberg et al. 2005).

For each sample, we generated a vertical profile (i.e. perpendicular to the longitudinal axis) based on sequential discrete ablations through the core (Ruttenberg et al. 2005). Profiles consisted of 30 pits (fewer in some of the smaller otoliths that had been polished much thinner than the average), starting from the polished surface of the otolith, above the region visually identified as containing the core. Each pit was formed by 8 laser pulses, but each varied in its dimensions due to both technical and natural reasons. Pits became progressively shallower and narrower due to the inferior focus of the laser as it progressed deeper into the transect. This resulted in differences in the sample size of each pit, which became pronounced in the number of Ca counts (which was up to 4 -fold higher at the beginning of the transect in comparison to its end). Other differences in $\mathrm{Ca}$ readings occurred along the transect independently of their location along it. Since similar relative fluctuations were observed on both sides of the core, we believe that these were the result of different 
aragonite qualities of different increments. While it was not possible to measure the depth of each pit, we determined that a distance of 22 to $24 \mu \mathrm{m}$ above the core (composed of 20 to 26 increments) was transected by 14 to 16 pits. Hence, we estimate that the average pit depth from surface to core is about $1.25 \mu \mathrm{m}$ and that each pit sampled slightly more than one increment.

From each pit we measured counts for ${ }^{24} \mathrm{Mg},{ }^{48} \mathrm{Ca}$, ${ }^{52} \mathrm{Cr},{ }^{55} \mathrm{Mn},{ }^{87} \mathrm{Sr},{ }^{138} \mathrm{Ba}$, and ${ }^{208} \mathrm{~Pb}$ in medium resolution mode $(\mathrm{R}=3000)$. Although $\mathrm{Ba}$ and $\mathrm{Sr}$ are often considered the best elements for otolith microchemistry studies (Campana 1999) and they can also be of help in identification of the core (Ruttenberg et al. 2005), we did not find these elements very useful for the PaSA. Both are found in relatively high concentrations all across the otolith. Although their concentrations might be a good indicator for temperature and salinity (as used in other studies, e.g. Campana 1999), we did not identify in our transects the same spikes that were found in other ultra-trace elements, and which could have been useful for our method (Ben-Tzvi et al. 2007a). Moreover, we found Mn and Mg to be the best core identifiers, making Ba and Sr useless for this purpose too. Thus, for otoliths collected in 2005, we decided to abandon ${ }^{138} \mathrm{Ba}$ and to measure ${ }^{63} \mathrm{Cu}$ instead.

Calibration standard solutions were prepared using calcium concentrations that generated similar ${ }^{48} \mathrm{Ca}$ signals to ablated otoliths. The analyte to ${ }^{48} \mathrm{Ca}$ ratios of the calibration standards were used to estimate the instrument mass bias. Mass bias-corrected sample analyteto- ${ }^{48} \mathrm{Ca}$ ratios were converted to elemental ratios using the known natural abundances of the stable isotopes. The calibration solutions were prepared in a $1 \%$ nitric acid matrix. All signals from ablated material were collected while aspirating a blank $1 \%$ nitric acid solution to mimic the ICP torch conditions that exist when analyzing the calibration solutions. Calibration standards were analyzed following every third sagitta.

Solid glass standard reference material (NIST 612) was analyzed at the beginning and end of each working day in order to evaluate the instrument's analytical accuracy. Estimated precision, measured as \%RSD (relative standard deviation $=\mathrm{CV})$, ranged between 12 and $19 \%$ for $\mathrm{Mg}: \mathrm{Ca} ; 2$ and $16 \%$ for $\mathrm{Mn}: \mathrm{Ca}_{i} 14$ and $26 \%$ for $\mathrm{Sr}: \mathrm{Ca} ; 11$ and $17 \%$ for $\mathrm{Ba}: \mathrm{Ca}_{;} 11$ and $16 \%$ for $\mathrm{Cr}: \mathrm{Ca} ;$ and $19 \%$ for $\mathrm{Pb}: \mathrm{Ca}$; and 13 and $21 \%$ for $\mathrm{Cu}: \mathrm{Ca}$. Blank samples were acquired only when aspirating $1 \% \mathrm{HNO}_{3}$ after every sagitta sample and set of standards. Elemental counts for each sagitta pit were blank-subtracted using the blank sample analyzed before each sagitta.

Element signal analysis. Our analyses focused on the profiles of $\mathrm{Cr}, \mathrm{Pb}, \mathrm{Mn}$ and, in 2005, $\mathrm{Cu}$ (other analyzed elements were found to be uninformative for the applied method; Ben-Tzvi et al. 2007a). Relevant infor- mation for each element was extracted using PaSA, which identifies non-random LA-ICPMS signals that fall below the customary detection limit (DL). A palindrome, in this context, is a sequence of concentration signals generated when transecting the otolith through the core, and whose symmetry about the core is unlikely $(<5 \%)$ to be the result of chance (for additional details and rationale see Ben-Tzvi et al. 2007a). Following identification of the spikes that make the palindrome, we counted the number of spikes for each of the examined elements. We considered 2 variables for each element: (1) the number of spikes recorded in the first 14 pits, starting from (or near) the core; and (2) the distance (measured in pits) from the core to the nearest signal. Previous work has shown the number of pits to correlate highly with physical distance (Ruttenberg et al. 2005). Here too, the distance of 22 to $24 \mu \mathrm{m}$ on the upper (sulcus) side, which is the estimated width of the pelagic otolith section (from the settlement mark to the core), was ablated by a similar number of 14 to 16 pits. While the increments on the proximal side are much thinner, progressively shallower pits along the transect indicate that a similar number of pits covers the same number of increments as on the distal side (as evidenced by signal symmetry).

The PaSA method can be reliably applied only when the otolith core is clearly identifiable-e.g. by its relatively high concentration of $\mathrm{Mn}$ and $\mathrm{Mg}$ (Ruttenberg et al. 2005). Using the same methods described by Ruttenberg et al. (2005), we found that the otolith cores of Chromis viridis were also characterized by high $\mathrm{Mn}$ and $\mathrm{Mg}$ concentrations (although a high variation of these concentrations in the core was observed). We discarded otoliths for which the core was not positively identified by both elements (due to missing the core or cracks in the otolith). Similarly, we discarded otoliths for which a clear palindrome was not identified (due to contamination or cracks in the otolith) for all 3 (or 4) elements. It should be noted that counts both below and above DL were considered and when a spike above DL had no paired spike on the other side of the core, it was considered contaminated. However, occasionally we were unable to identify the palindrome (see 'Results'); when this occurred, noises in the readings of several elements were identified. When there were fewer than 14 pits on one side of the core, spikes that were found only in the longer tail and were at least of the same magnitude as those found in pairs were considered real signals. However, all otoliths in which one tail was shorter than 9 pits were discarded.

Statistical analyses. To analyze the microchemical data we opted for a data-reduction procedure rather than a classification procedure. The rationale for our choice was simple: classification factors are constructed (ad hoc) to maximize the resolution between 
a priori defined classes (collection sites). However, for a population of immigrants of potentially different origins, settlers at a particular site need not share higher (chemical) similarity than with settlers at other sites. On the other hand, data-reduction procedures construct factors that simply maximize (sequentially) the variance in the original variables, regardless of ultimate class membership. Class composition, examined in terms of factor scores, could thus offer greater insight into the immigration process that led to class formation. For example, imagine 2 sites that receive larvae via 3 different dispersal routes, each leaving a characteristic chemical signature: a composite of the different element concentrations designed to maximize the overall chemical difference between the larvae collected at the 2 sites would necessarily distort the chemical information.

We used principle component analysis (PCA) to evaluate the standardized PaSA data of each of 4 cohorts: 2003 ( $\mathrm{n}=17)$, Early $04(\mathrm{n}=47)$, Late $04(\mathrm{n}=79)$ and $2005(\mathrm{n}=129)$. Bartlett's test of sphericity was applied to test the null hypothesis that the correlation matrix is an identity matrix. Rejection of the null is a standard precondition for running PCA. Bivariate plots of the scores along the first and second principle components indicated that differences among the sites are obtained only along the first component (PC1). Hence, we limited our attention to PC1 scores, particularly their frequency distribution at a resolution of 0.25 standarddeviation units. PCA was also used to examine the standardized, relative (to Ca) concentrations of trace elements in the core. We focus our analysis on the 2005 sample, as it covers the greatest geographic extent.

\section{RESULTS}

\section{Estimating PLD and recruitment dates}

PLD estimates were obtained for $92 \%$ of the fish examined $(\mathrm{n}=328)$. We could not read $6 \%$ of the fish, and the $\mathrm{CV}$ of the remaining $2 \%$ was higher than 0.05 . As post-settlement increments were harder to read, good estimates of total age were possible for only $84 \%$ of the fish. Overall, otolith analysis from fish collected at the Eilat sites (Fig. 1) fell into one of 2 PLD categories: younger recruits whose otoliths averaged 21.94 \pm 0.26 (SD) increments from the core to the settlement mark (range: 21 to 23 ; termed ' $22 \mathrm{~d}$ recruits'), and older recruits whose otoliths averaged $26.09 \pm 0.29$ increments (range: 25 to 27 ; termed ' $26 \mathrm{~d}$ recruits'). The former included all of the fish collected at IUI, $47.6 \%$ of the Late 04 DR collection, and varying proportions of the NB collection: 1 fish from Early 04, 2 fish from Late 04 , and $42.9 \%$ of the 2005 collection. All the other fish, including all those collected from Aqaba, belonged to the $26 \mathrm{~d}$ recruits (Fig. 1).

\section{Chemical analysis}

Raw chemical data were obtained for 316 fish (out of 328). From these we were able to obtain 272 profiles that met the PaSA criteria. We omitted certain otoliths when the core could not be identified ( 25 fish), when one side of the profile was shorter than 9 pits (16 fish) or when we could not identify a clear palindrome (3 fish).

The proportion of the total variance in PaSA data explained by the first principle component ranged from 37.5 to $68.8 \%$, with the correlation between PC1 and most dependent variables exceeding 0.6 (Table 1). The direction of these correlations implies that higher PC1 scores reflect lower trace element concentrations in the otolith. When broken down to sites and PLD categories, a semi-quantitative evaluation of the frequency distribution of $\mathrm{PC} 1$ scores revealed several trends (Fig. 2). First, most of the $22 \mathrm{~d}$ recruits occupied the left mode of the PC1 score distribution. This group includes all the recruits collected at IUI, and some of those collected at NB and DR. Most of the recruits collected at NB had longer PLDs ( 26 d) and higher PC1 scores. Recruits collected at DR shared similar PC1 scores and PLDs with those collected at NB and, in the Late 2004 sample, with those collected at IUI. Second, recruits collected at MSS and SB had PLDs of $\sim 26 \mathrm{~d}$, and could be divided into 2 distinct groups based on their PC1. One of the groups (termed ' $b$ ') was similar in PC1 scores to the IUI and younger NB groups (but had longer PLDs). The second, 'cleaner' (i.e. fewer elemental concentration spikes as

Table 1. Chromis viridis. Principle component analysis of chemical data obtained by palindrome sequence analysis (PaSA) of otoliths. Top: correlations between PC1 and the dependent variables. Bottom: proportion of total variance in PaSA data explained by the first principle component and results of Bartlett's test of sphericity $\left({ }^{* * *} \mathrm{p}<0.001\right)$

\begin{tabular}{|lcccr|}
\hline & 2003 & Early 04 & Late 04 & 2005 \\
\hline 1 st Cr & 0.837 & 0.555 & 0.519 & 0.862 \\
$1 \mathrm{st} \mathrm{Pb}$ & 0.92 & 0.676 & 0.523 & 0.808 \\
1 st Mn & 0.285 & 0.508 & 0.664 & 0.762 \\
1 st Cu & & & & 0.762 \\
Total Cr & -0.819 & -0.586 & -0.718 & -0.885 \\
Total Pb & -0.837 & -0.692 & -0.716 & -0.866 \\
Total Mn & -0.365 & -0.635 & -0.729 & -0.828 \\
Total Cu & & & & -0.852 \\
Variance (\%) & 52.2 & 37.5 & 42.4 & 68.8 \\
$\chi^{2}$ & $46^{* * *}$ & $84^{* * *}$ & $129^{* * *}$ & $818^{* * *}$ \\
\hline
\end{tabular}



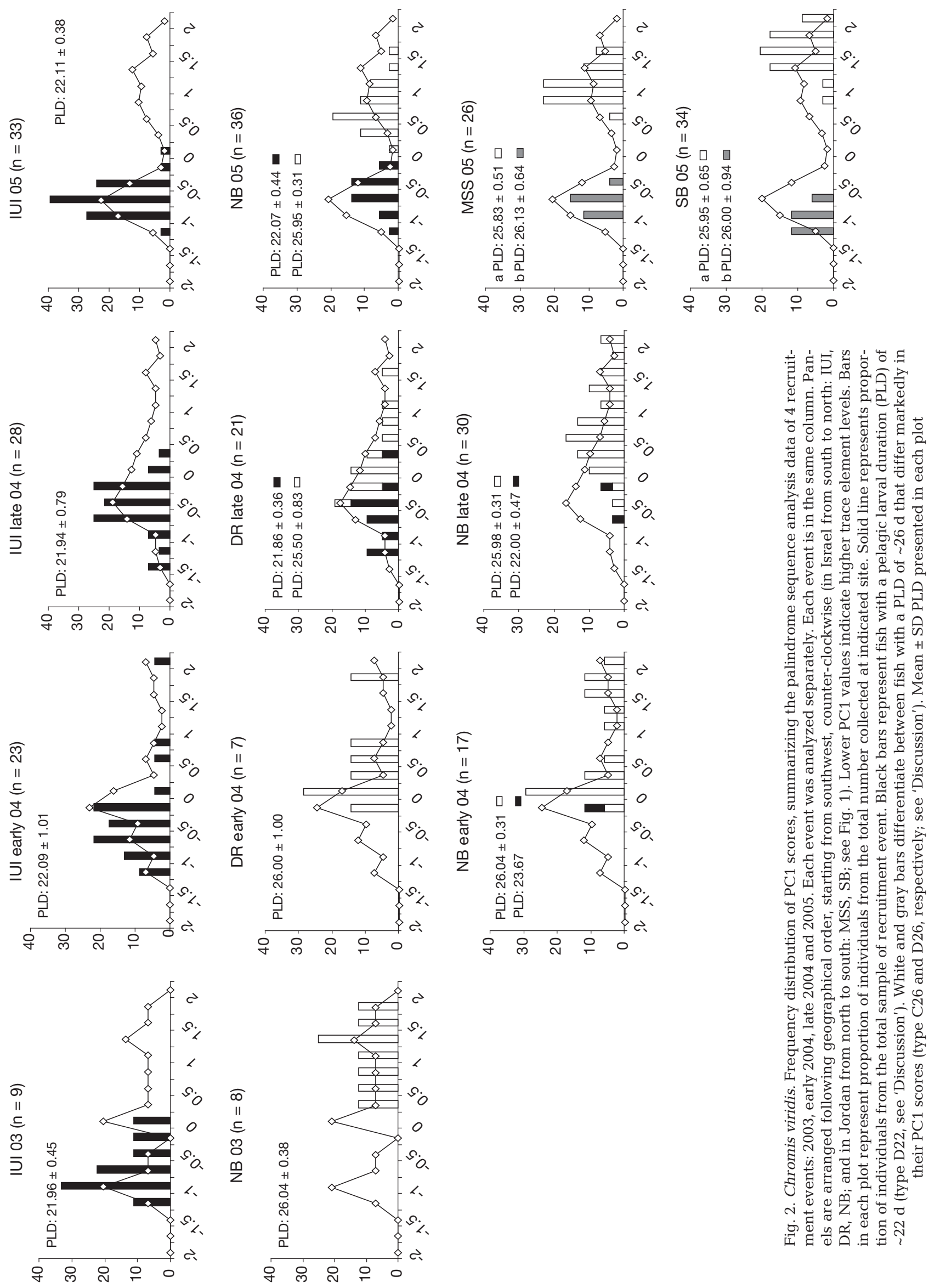
Table 2. Chromis viridis. Principal component analysis of trace-element concentrations in the otolith cores of the 2005 sample. Provided are the loadings of the first 3 components and the variation explained by each. Bartlett's test of sphericity: $\chi^{2}=56.7, \mathrm{p}<0.001$

\begin{tabular}{|lrrr|}
\hline Element & \multicolumn{1}{c}{ 1st } & 2nd & \multicolumn{1}{c|}{ 3rd } \\
\hline $\mathrm{Mg}$ & 0.507 & 0.630 & 0.306 \\
$\mathrm{Cr}$ & -0.661 & 0.395 & -0.100 \\
$\mathrm{Cu}$ & -0.457 & 0.459 & 0.360 \\
$\mathrm{Sr}$ & 0.081 & -0.591 & 0.510 \\
$\mathrm{~Pb}$ & -0.262 & -0.058 & 0.766 \\
$\mathrm{Mn}$ & 0.827 & 0.223 & 0.124 \\
Variance (\%) & 27.7 & 19.5 & 18.3 \\
\hline
\end{tabular}

evidenced by higher PC1 scores) group (termed 'a') was similar in PLD and PC1 scores to the older NB group. Third, the distribution of PC1 scores of the longer PLD, higher PC1 individuals settling at the SB, MSS and NB shifted significantly toward lower PC1 values from the southern Jordanian site (SB) through the MSS to the northernmost NB site (KolmogorovSmirnov $Z$-test_SB vs. MSS: $Z=0.93, \mathrm{p}=0.028$; MSS vs. NB: $Z=1.04, \mathrm{p}=0.036$ ). Altogether, a consistent spatial structure in the chemical signature of the recruits was found (Fig. 2). Except for the minor groups (b) at the MSS and $\mathrm{SB}$, this spatial structure resembled that of the PLDs.

Of the variation in trace-element concentration in the otolith cores of the 2005 sample, 27.7, 19.4 and $18.3 \%$ was explained by the first 3 principle components, respectively (Table 2). Pairwise plots of the 3 components exposed no structure based on settlement site and/or PLD category (Fig. 3).

\section{DISCUSSION}

Given spatial heterogeneity in trace element concentrations in coastal environments, variation in the number and position of element signals in the otoliths of new recruits (e.g. Fig. 4) can potentially distinguish between distinct larval dispersal routes. However, on many occasions, as in this study, most of the data obtained by LA-ICPMS cannot be exploited due to element readings that are lower than the threshold for instrument detection (i.e. DL). The PaSA method may enable a reliable identification of trace element signals in LA-ICPMS data (including those below the DL), which are presumed indicative of the presence of these elements in the water engulfing the dispersing larvae (Ben-Tzvi et al. 2007a). Only by adopting the PaSA approach were we able to obtain meaningful results from a high proportion of chemically analyzed otoliths.

Despite the efficient identification of chemical profiles using PaSA, it is still impossible to directly associate the element signals in the otolith with specific geographic locations. This limitation is mainly related to 2 factors: (1) a lack of detailed information on trace element concentrations in the sea from the northern Gulf of Aqaba, and (2) a lack of knowledge of the exact relation of water-otolith element concentrations. To obtain some indirect indication of the directionality of larval movement and possible source sites of recruits, we took into account 5 indicators in our conceptual analysis. These indicators, which enabled a better discrimination among post-recruit types, their trajectories and overall directionality of dispersal, comprised (1) age of recruits, (2) timing of arrival of recruits at the studied sites, (3) timing of reproduction at the studied sites,
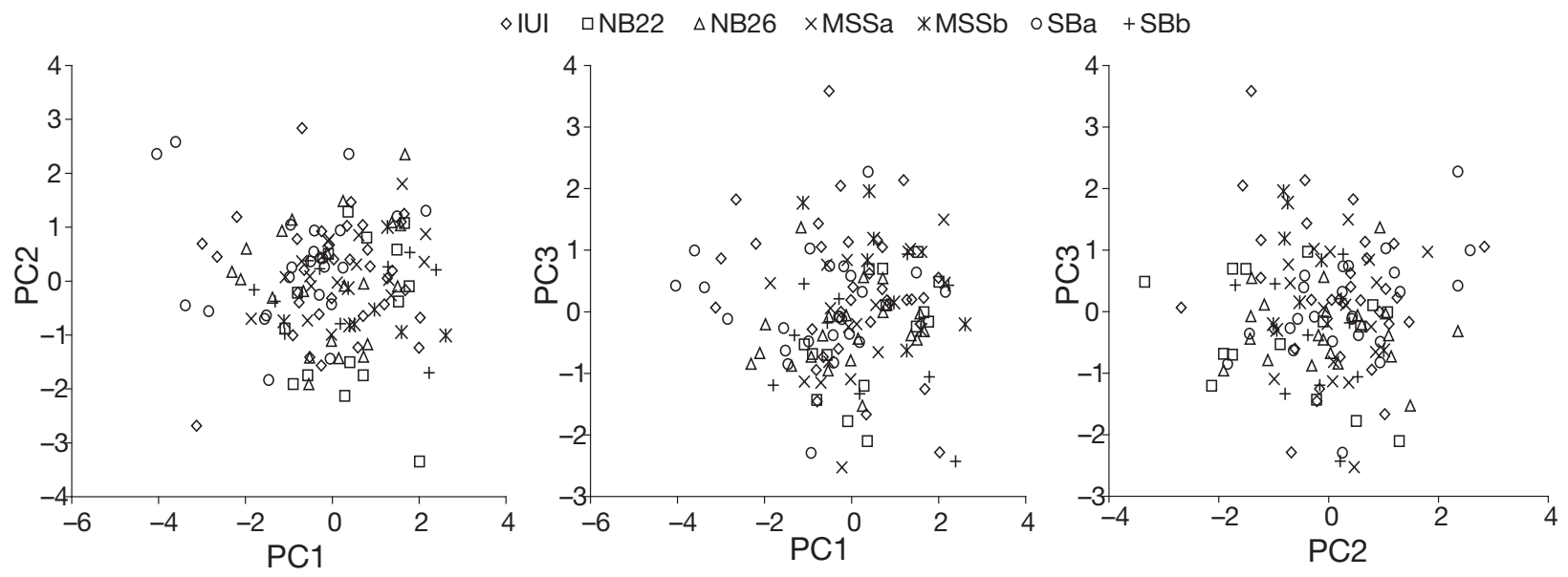

Fig. 3. Chromis viridis. Results of principal component analysis comparing core element concentrations of all fish collected in 2005. Pairwise plots of 3 main principal components (PC) show a high variation and mixing of members of all groups, with no connection to the types that were defined by the site of collection, the pelagic larval duration or the palindrome sequence analysis results. Type D22 groups: IUI \& NB22. Type C26 groups: NB26, MSSa and SBa. Type D26 groups: MSSb and SBb 


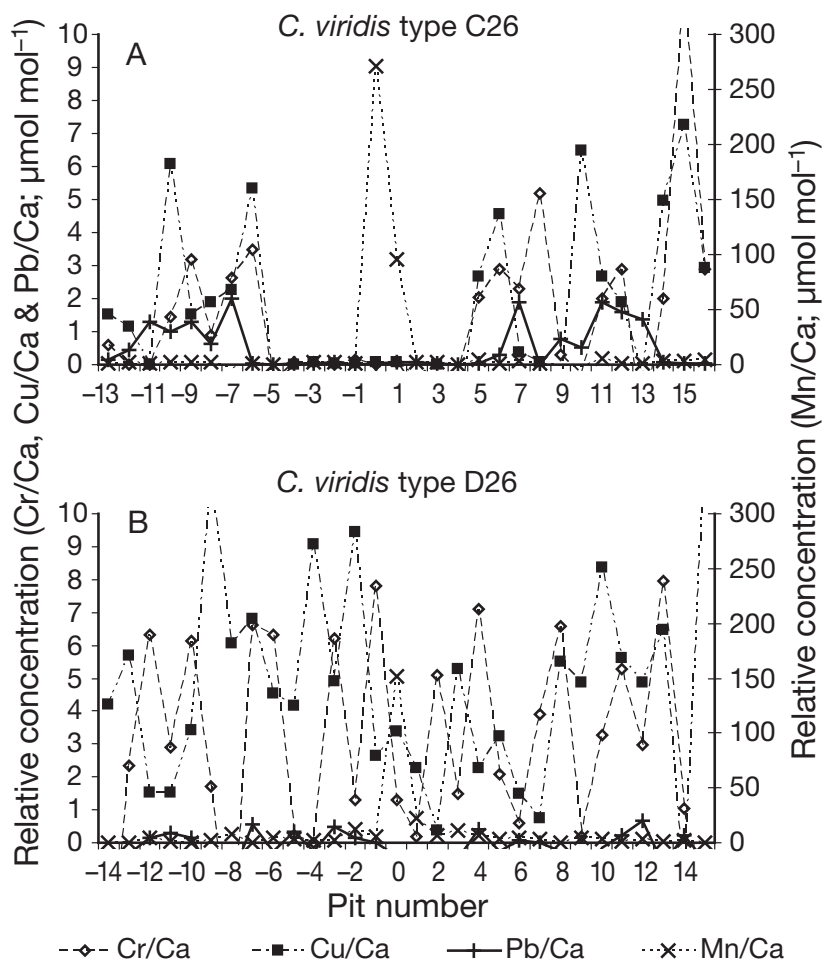

Fig. 4. Chromis viridis. Laser ablation inductively coupled plasma mass spectrometry concentration profiles for 4 elements $(\mathrm{Mn}, \mathrm{Cr}, \mathrm{Cu}$ and $\mathrm{Pb})$, in sagittae of 2 recruits collected at the same time from the same coral at SB. The $x$-axis represents distance, in pits, from the core, identifiable by a relatively high concentration of $\mathrm{Mn}$ (and $\mathrm{Mg}$, which is not shown here), and positioned at ' 0 '. Values along the $y$-axis are element concentrations, expressed in relative units to the concentration of $\mathrm{Ca}$. Note the differences in element spikes distribution between (A) a 'clean' otolith (C26 type) and (B) a 'dirty' otolith (D26 type)

(4) chemical signal distribution in the otoliths, and (5) spatial distribution of pollution hotspots along the northern Gulf of Aqaba.

Based on these 5 indicators, we distinguished between 3 'types' of larvae that settle along the $35 \mathrm{~km}$ shoreline of the northern Gulf of Aqaba: (1) larvae with a mean PLD of $\sim 26 \mathrm{~d}$ and a relatively 'clean' otolith, which were collected from the east and north coasts at DR, NB, MSS and SB (termed 'C26,' Fig. 4A), (2) larvae with a mean PLD of $\sim 26 \mathrm{~d}$ and a relatively 'dirty' otolith, which were collected from the east coast (Jordan) at MSS and SB (termed 'D26,' Fig. 4B), and (3) larvae with a mean PLD of $\sim 22 \mathrm{~d}$ and a relatively 'dirty' otolith, which were collected from the west coast (Israel) mostly from IUI, but also from DR and NB (termed 'D22').

These 5 indicators may also contribute to obtaining some idea of the directionality of larval movement. First, the south-north gradient in PC1 score of the C26 recruit group along the Jordanian shore appears consistent with northward dispersal along the eastern coastline of the gulf (Fig. 2, plots of SB 05, MSS 05 and all NB), which parallels a corresponding increase in anthropogenic activity from the Saudi to the Jordanian shores. Importantly, it was the inner region of C26 otoliths (i.e. corresponding to the early larval stage) that was clean of contaminants and responsible for the relatively high PC1 scores of this group (Fig. 4). Second, the limited and occasional recruitment of D22 larvae at the DR and NB sites may suggest a northward migration along the western coastline, presumably commencing along the eastern shores of the Sinai Peninsula, which are experiencing high levels of anthropogenic activity. Consistent with these inferences of directionality is the observation that recruitment in the northern tip of the gulf commences several weeks prior to the onset of reproduction by the local adult population (O. Ben-Tzvi unpubl. data)

At present we have no verifiable explanation for recruits of type D26, which exhibited a similar distribution of PC1 scores as those of type D22, but were considerably older at settlement. The similarity in signal profiles of D22 and D26 recruits suggests that the latter may simply be older D22 larvae that had been transported to the east shore, either along a cross-gulf trajectory or along a trajectory that would lead them southward after having reached the northern tip of the gulf (all within the area of high anthropogenic activity and, thus, with expectedly similar chemical signatures). We examined the width of daily otolith increments in an attempt to find evidence for differences in the growth rates between the different groups. Such evidence, had it been found at the later (outer) part of the otolith's larval section, might have supported a possibility for common source of both D26 and D22 fish. No such evidence was found, however (O. Ben-Tzvi, O. Polak, M. Kiflawi unpubl. data). Moreover, we are not aware of any oceanographic or environmental conditions that would either explain or reject one of the above-mentioned (or any other) scenarios.

As opposed to the PaSA results, which revealed a fairly clear picture of 3 distinct fish groups, the otolith cores, which are expected to reflect conditions at the natal sites (and ideally also their locations), follow no clear pattern (Fig. 3). The lack of structure can be explained in one of 2 ways: (1) early mixing of larvae and later separation into the observed groups; or (2) core chemistry that cannot be used to distinguish between natal areas. An initial random mixing of larvae is unlikely given the spatial structure of the hydrology of the northern Gulf of Aqaba (as described below), and in light of the fact that some of the differences that distinguish between the 3 larval types (D22, C26 and D26) can be ascribed to early larval stages (Fig. 4). On the other hand, several recent studies have 
shown that element composition at the core is not always a good indicator of the chemical composition of the ambient water (Patterson et al. 2004b, de Vries et al. 2005, Ruttenberg et al. 2005, Warner et al. 2005, Chittaro et al. 2006). Moreover, we emphasize that, unlike the PaSA data, core-chemistry data are based on actual concentrations and are thus prone to the various types of error inherent to LA-ICPMS analysis of otolith chemistry (Ben-Tzvi et al. 2007a). Based on the above, we suggest that, in the case of Chromis viridis, the results obtained from the PaSA are the most useful in reconstructing the recruits' history.

The distance between both sides of the narrow gulf ( 5 to $15 \mathrm{~km}$ ) is not expected to be a barrier preventing the larvae from crossing from one side to the other. Thus, the observed separation between the 2 trajectories along the west and east coasts should be explained by factors other than distance. The current regime might be a major controlling factor. The current flow in the gulf is affected by wind, tides and buoyancy fluxes (Berman et al. 2000, Monismith \& Genin 2004). The main near-shore currents are alongshore, with frequent changes in magnitude and direction (Genin \& Paldor 1998, Ben-Tzvi et al. 2007b), and their main component is tide driven (O. Ben-Tzvi et al. unpubl. data). A recent study of the surface flow has revealed occasional clear separations between 2 water bodies on the eastern and western sides of the gulf $(\mathrm{H}$. Gildor \& E. Fredj unpubl. data). However, the lengths of time that these conditions have existed, and their spatial extents, are still unknown. Moreover, the known average currents in the gulf are not likely to prevent the fish larvae from proceeding against the flow along the coast. Hence, we assume that the main factors dictating the suggested trajectories are probably both flow regime and larval behavior.

Plasticity in the PLD of reef fishes is well documented and common in labrids (Sponaugle et al. 2006) and gobies (Bay et al. 2006). The PLD of pomacentrids is less variable (Thresher et al. 1989, Wellington \& Victor 1989) and the limited intra-specific variation is rarely found within cohorts that recruit to the same site at the same time (Bay et al. 2006). In the present study, the coupling between mean PLD and PC1 score of the larval types settling at IUI and NB was remarkably consistent among years, making the among-type difference in mean PLD highly enigmatic.

Environmental conditions may play an important role in affecting otolith element characteristics and (whether similar or differing conditions) in affecting the fishes' PLD; therefore, they could be responsible for the differences found between otoliths and fish age at recruitment. For example, differences in sea temperature might affect the growth rate (somatic and otolith) of the larvae due to changes in their metabolism. How- ever, environmental conditions (sea surface temperature, nutrient concentrations, plankton biomass and chlorophyll) along the eastern and western shores of the gulf are very similar (RSMPP 2003), and are unlikely to be the cause of the differences observed in this study. SST data for the northern gulf present a small difference between the 2 shorelines (the eastern shore is $\sim 1^{\circ} \mathrm{C}$ cooler), but this difference is much smaller than the seasonal changes (Al-Rousan et al. 2002), which in 2004 resulted in no significant difference in the mean PLD between the early and late cohorts. Similarly, a preliminary molecular study comparing a sequence of the D-loop region of recruits of the 3 types (D22, D26 and C26) did not support the existence of isolated populations that might provide a genetic basis for the difference in PLD (O. Ben-Tzvi, G. Bernardi, R. Beldade unpubl. data).

This study applied the newly proposed PaSA approach in an attempt to distinguish between the dispersal routes followed by coral reef fish larvae. We have shown that LA-ICPMS data, of which most would have been traditionally ignored as 'sub-detection limit,' can be valuable in distinguishing between such routes. While this study falls short of direct geographic identification of the dispersal routes of Chromis viridis in the northern Gulf of Aqaba, it does provide a rare and clear demonstration of the heterogeneity in the dispersal routes that feed local populations, even when these are separated by relatively short distances. The findings imply that the fish populations of the northern gulf reefs (i.e. Aqaba and Eilat) are fed mainly by external sources of larvae, most probably from reefs along the Saudi and Sinai (Egypt) coasts. The practical implication of the study findings is that any sound management plans or conservation measures for coral reefs in the gulf need to be regional and, ideally, should also involve collaboration among all the coastal countries of the Gulf of Aqaba.

Acknowledgements. This study was funded by the US-Israel Bi-National Science Foundation (BSF) through a grant to S.D.G. and A.A.; the Red Sea Marine Peace Park (RSMPP) program of the US Agency for International DevelopmentMiddle Eastern Regional Cooperation (USAID-MERC) to A.A.; a Boxenbaum-Neta Foundation grant to O.B.; and by an Israel Science Foundation grant to M.K. ICPMS analyses at the University of California, Santa Barbara were supported by the A. W. Mellon Foundation, and PISCO, the Partnership for Interdisciplinary Studies of Coastal Oceans, funded by the David and Lucille Packard, and the Gordon and Betty Moore Foundations. The authors thank Ms. N. Paz for her editorial assistance. We also thank the directors and staff of the Marine Biology Laboratories of Eilat and Aqaba for their hospitality and the use of lab facilities, and Mr. O. Polak for his help in the sea and preparation of the samples. We also thank 3 anonymous referees for their constructive reviews of this manuscript. 


\section{LITERATURE CITED}

Al-Rousan S, Al-Moghrabi S, Pätzold J, Wefer G (2002) Environmental and biological effects on the stable oxygen isotope records of corals in the northern Gulf of Aqaba, Red Sea. Mar Ecol Prog Ser 239:301-310

Allison GW, Lubchenco J, Carr MH (1998) Marine reserves are necessary but not sufficient for marine conservation. Ecol Appl 8:S79-S92

Allison GW, Gaines SD, Lubchenco J, Possingham HP (2003) Ensuring persistence of marine reserves: catastrophes require adopting an insurance factor. Ecol Appl 13(sp1): $8-24$

> Almany GR, Berumen ML, Thorrold SR, Planes S, Jones GP (2007) Local replenishment of coral reef fish populations in a marine reserve. Science 316:742-744

Bay LK, Buechler K, Gagliano M, Caley MJ (2006) Intraspecific variation in the pelagic larval duration of tropical reef fishes. J Fish Biol 68:1206-1214

Ben-Tzvi O, Abelson A, Gaines SD, Sheehy MS, Paradis GL, Kiflawi M (2007a) The inclusion of sub-detection limit LAICPMS data, in the analysis of otolith microchemistry, by use of a palindrome sequence analysis (PaSA). Limnol Oceanogr Methods 5:97-105

Ben-Tzvi O, Kiflawi M, Gildor H, Abelson A (2007b) Possible effects of downwelling on the recruitment of coral reef fishes to the Eilat (Red Sea) coral reefs. Limnol Oceanogr 52:2618-2628

Berman T, Paldor N, Brenner S (2000) Simulation of wind-driven circulation in the Gulf of Eilat (Aqaba). J Mar Syst 26: 349-365

$>$ Caley MJ, Carr MH, Hixon MA, Hughes TP, Jones GP, Menge BA (1996) Recruitment and the local dynamics of open marine populations. Annu Rev Ecol Syst 27:477-500

Campana SE (1999) Chemistry and composition of fish otoliths: pathways, mechanisms and applications. Mar Ecol Prog Ser 188:263-297

Chittaro PM, Hogan JD, Gagnon J, Fryer BJ, Sale PF (2006) In situ experiment of ontogenetic variability in the otolith chemistry of Stegastes partitus. Mar Biol 149:1227-1235

> de Vries MC, Gillanders BM, Elsdon TS (2005) Facilitation of barium uptake into fish otoliths: influence of strontium concentration and salinity. Geochim Cosmochim Acta 69: 4061-4072

- Gaines SD, Bertness M (1993) The dynamics of juvenile dispersal: why field ecologists must integrate. Ecology 74 : 2430-2435

Genin A, Paldor N (1998) Changes in the circulation and current spectrum near the tip of the narrow seasonally mixed Gulf of Elat. Isr J Earth Sci 47:87-92

Jones GP, Milicich MJ, Emslie MJ, Lunow C (1999) Selfrecruitment in a coral reef fish population. Nature 402: 802-804

Jones GP, Planes S, Thorrold SR (2005) Coral reef fish larvae settle close to home. Curr Biol 15:1314-1318

Lo-Yat A, Meekan M, Munksgaard N, Parry D, Planes S, Wolter M, Carleton J (2005) Small-scale spatial variation in the elemental composition of otoliths of Stegastes nigricans (Pomacentridae) in French Polynesia. Coral Reefs 24: 646-653

Initial editorial responsibility: Howard Browman, Storebø, Norway (until November 5, 2007); Final editorial responsibility: Matthias Seaman, Oldendorf/Luhe, Germany
Lubchenco J, Palumbi SR, Gaines SD, Andelman S (2003) Plugging a hole in the ocean: the emerging science of marine reserves. Ecol Appl 13(sp1):3-7

Monismith SG, Genin A (2004) Tides and sea level in the Gulf of Aqaba (Eilat). J Geophys Res-Oceans 109:C04015

> Mora C, Sale PF (2002) Are populations of coral reef fish open or closed? Trends Ecol Evol 17:422-428

- Palmer MA, Allan JD, Butman CA (1996) Dispersal as a regional process affecting the local dynamics of marine and stream benthic invertebrates. Trends Ecol Evol 11: 322-326

Patterson HM, Kingsford MJ (2005) Elemental signatures of Acanthochromis polyacanthus otoliths from the Great Barrier Reef have significant temporal, spatial, and betweenbrood variation. Coral Reefs 24:360-369

> Patterson HM, Thorrold SR, Shenker JM (1999) Analysis of otolith chemistry in Nassau grouper (Epinephelus striatus) from the Bahamas and Belize using solution-based ICPMS. Coral Reefs 18:171-178

> Patterson HM, Kingsford MJ, McCulloch MT (2004a) Elemental signatures of Pomacentrus coelestis otoliths at multiple spatial scales on the Great Barrier Reef, Australia. Mar Ecol Prog Ser 270:229-239

Patterson HM, Kingsford MJ, McCulloch MT (2004b) The influence of oceanic and lagoonal plume waters on otolith chemistry. Can J Fish Aquat Sci 61:898-904

> Roberts CM (1997) Connectivity and management of Caribbean coral reefs. Science 278:1454-1457

Roberts CM, Hawkins JP (1997) How small can a marine reserve be and still be effective? Coral Reefs 16:150

RSMPP (2003) The Red Sea Peace Park cooperative research, monitoring and management program, final report-phase 1. US-AID and NOAA

Ruttenberg BI, Warner RR (2006) Spatial variation in the chemical composition of natal otoliths from a reef fish in the Galápagos Islands. Mar Ecol Prog Ser 328:225-236

- Ruttenberg BI, Hamilton SL, Hickford MJH, Paradis GL and others (2005) Elevated levels of trace elements in cores of otoliths and their potential for use as natural tags. Mar Ecol Prog Ser 297:273-281

Sponaugle S, Grorud-Colvert K, Pinkard D (2006) Temperature-mediated variation in early life history traits and recruitment success of the coral reef fish Thalassoma bifasciatum in the Florida Keys. Mar Ecol Prog Ser 308: $1-15$

> Swearer SE, Caselle JE, Lea DW, Warner RR (1999) Larval retention and recruitment in an island population of a coral-reef fish. Nature 402:799-802

Thresher RE, Colin PL, Bell LJ (1989) Planktonic duration, distribution and population structure of western and central Pacific damselfishes (Pomacentridae). Copeia 420-434

Warner RR, Cowen RK (2002) Local retention of production in marine populations: Evidence, mechanisms, and consequences. Bull Mar Sci 70:245-249

Warner RR, Swearer SE, Caselle JE, Sheehy M, Paradis G (2005) Natal trace-elemental signatures in the otoliths of an open-coast fish. Limnol Oceanogr 50:1529-1542

Wellington GM, Victor BC (1989) Planktonic larval duration of 100 species of Pacific and Atlantic damselfishes (Pomacentridae). Mar Biol 101:557-567

Submitted: September 18, 2007; Accepted: November 19, 2007 Proofs received from author(s): April 27, 2008 